\title{
Impact of Job Satisfaction of Employees and Organizational Culture in Banks on Receptiveness to Change, Cooperation among Peers, Team Orientation, Organizational Goal Identity and Union Management Cooperation
}

\author{
Ms Priya Vij ${ }^{1}$, Ms Sapna Suri ${ }^{2}$, Sukhbir Singh ${ }^{3}$ \\ ${ }^{1,2}$ (Department of Business Management, Padmashree Dr.D.Y.Patil University, India) \\ ${ }^{3}$ (Student, Indira Gandhi National Open University, New Delhi, India)
}

\begin{abstract}
Job satisfaction is how content an individual is with his or her job. Scholars and human resource professionals generally make a distinction between affective job satisfaction and cognitive job satisfaction. Affective job satisfaction is the extent of pleasurable emotional feelings individuals have about their jobs overall, and is different to cognitive job satisfaction which is the extent of individuals' satisfaction with particular facets of their jobs, such as pay, pension arrangements, working hours, and numerous other aspects of their jobs.In the current study, employees were asked to indicate their level of satisfaction for different aspects of job like salary, relationships with peers, organizational structure, cooperation of managers etc.This research paper emphasizes on 16 items (job aspects) for which employees had to state their level of satisfaction or dissatisfaction on a five-point scale. This Study has bought out Impact of Job Satisfaction of Employees and Organizational Culture in Banks on Receptiveness to Change, Cooperation among Peers, Team Orientation, Organizational Goal Identity, Union Management Cooperation, etc. At its most general level of conceptualization, job satisfaction is simply how content an individual is with his or her job. At the more specific levels of conceptualization used by academic researchers and human resources professionals, job satisfaction has varying definitions. Affective job satisfaction is usually defined as a unidimensional subjective construct representing an overall emotional feeling individuals have about their job as a whole. Hence, affective job satisfaction for individuals reflects the degree of pleasure or happiness their job in general induces. Cognitive job satisfaction is usually defined as being a more objective and logical evaluation of various facets of a job. As such, cognitive job satisfaction can be unidimensional if it comprises evaluation of just one aspect of a job, such as pay or maternity leave, or multidimensional if two or more facets of a job are simultaneously evaluated.
\end{abstract}

Keywords: Affective Job satisfaction, Cognitive, Goal Identity, Team Orientation, Union Management

\section{Introduction}

In this study 'Job' means the total relationship between the individual employees and his employer (organization) and with work for which he gets compensated. The term 'Satisfaction' refers to the simple feeling/state accompanying the attainment by an impulse of his/her objectives. The term 'Job Satisfaction' therefore refers to the favourableness with which employees view their work and the term 'Job Dissatisfaction' to the unfavourableness with which they take their work.

Various theories like Maslow's Need Hierarchy Theory, Herzberg's Motivation-Hygiene Theory, and Vroom's Expectancy Model have been extended to describe the factors responsible for the Job Satisfaction of the employees in the organization. Broadly we can say that an employee's 'Job Satisfaction' is related to a number of variables such as age, occupational level, size of the organization, organizational climate, educational qualifications, educational and economic background, size of the family, gender of the employee, etc.Bank Officers form a delicate link between the management and the clerical staff. The success of the bank depends upon the coordination, synchronization and cooperation of the Bank Officers with these two very divergent entities. Hence, the job satisfaction of the officers is of prime importance because only a satisfied and happy officer will be able to achieve such synergy in the bank. Therefore, this study assumes significance and relevance in the overall success of the bank.

A vast majority of studies have provided evidence for correlation between job satisfaction and participation. Researchers have also found a positive and linear relationship between age and job satisfaction. However, some researchers have found the opposite results. Many Indian scholars have studied the relationship between job satisfaction and various other personal factors like level of education, length of service, emoluments and job level. Studies that examined the role of both personal and organizational factors as determinants of job satisfaction have found that between the two sets of factors, organizational factors play a decisive role in influencing job satisfaction. 


\section{Objectives of the Study}

$>$ To study the significant and positive association between job satisfaction of employees and the organizational culture in both public and private sector banks

$>$ To study whether organizational culture of Public Sector Banks is significantly higher than that of the private sector banks.

\section{Literature Review}

The concept of job satisfaction is central to many aspects of industrial and organizational behavior. Locke $^{1}$ (1976) has defined job satisfaction "as a pleasurable emotional state resulting from the appraisal of one's job or job experiences".

Carnell and Wild ${ }^{2}$ (1974) explained the importance of the study of job satisfaction as a part of job attitudes stating that, Managements must of necessity be concerned with aspects such as work, payment systems, supervision etc, and with matching of such aspects with the characteristics of the worker to ensure not only favorable specific job attitudes but also the overall job satisfaction of workers.

Friedlander and Marguiles ${ }^{3}$ (1969) found organizational climate to be a significant determinant of job satisfaction. The dimensions of organizational climate found conducive to job satisfaction are opportunities for achievement, employee centered instead of task oriented climate, supportive climate and organizational clarity. In Indian studies Pratap and Srivastava ${ }^{8}(1985)$ reported a significant correlation between job satisfaction and organizational climate in a study of junior and middle level central government officers.

Sharma and Sharma ${ }^{9}(1989)$ found significant positive correlations between job satisfaction and dimensions of organizational climate. These correlations are higher for subordinates' terms of leadership and communication dimensions and higher officers in terms of interaction, influence, decision making and goal setting dimensions of organizational climate.

Kline and Boyd ${ }^{11}$ (1991) found that for higher-level managers, satisfaction was related to the organization's structure and context as well as to its climate, whereas for middle managers and vice presidents, job satisfaction was related more frequently to the organization's climate and less frequently to its structure and context.

In the same light Johnnesson ${ }^{12}$ (1973) stated that, "Job satisfaction and organizational climate are one and the same but with different brands of names.

\section{Data Analysis \& Results}

4.1. Difference in Job Satisfaction of Employees between Public and Private Sector Banks.

The results showed that staff and managers in "private" sector banks were more satisfied from various aspects of their job as compared to their counterparts in public sector banks. The Chi- square value showing comparison between staff of public and private sector was 32.901 at 4 degrees of freedom and this value showing comparison between managers of public and private sector banks was 10.064 at 4 degrees of freedom. Both these values were significant at $1 \%$ level of significance. Finally significant difference was also found in an overall comparison between public and private sector banks. Pratap \& Srivastava ${ }^{8}$ (1985) also reported significant differences between private \& public sector employees in terms of job satisfaction and organizational climate, with private firm employees being more satisfied and finding their organizational climate to be better. The Authors findings thus supported those of Pratap and Srivastava ${ }^{8}$.

Table 1 (a)

Job satisfaction of employees: Difference between public and private sector banks

\begin{tabular}{|l|l|l|l|}
\hline Type of bank & Employees below median & Employees above median & Total \\
\hline Public & $81(61 \%)$ & $51(39 \%)$ & 132 \\
\hline Private & $14(19 \%)$ & $58(81 \%)$ & 72 \\
\hline Total & 95 & 109 & 204 \\
\hline Chi square for staff $\mathbf{3 2 . 9 0 1 2} * *$ Degree of freedom $=\mathbf{1}$ & 84 \\
\hline Public & $50(60 \%)$ & $34(40 \%)$ & 51 \\
\hline Private & $16(31 \%)$ & $35(69 \%)$ & 135 \\
\hline Total & 66 & 29 & 216 \\
\hline Chi square for managers $=\mathbf{1 0 . 0 6 4 4 1} * *$ Degree of freedom $=1$ & 123 \\
\hline Public & $132(61 \%)$ & $84(39 \%)$ & 339 \\
\hline Private & $\mathbf{1}$ & 86 & \\
\hline Total & 169 & 170 & \\
\hline Chi square for all employees $=\mathbf{3 1 . 7 8 9} *$ Degrees of freedom $=\mathbf{1}$ & \\
\hline
\end{tabular}


Ahmed and Pestonji ${ }^{33}$ emphasized that, "Jobs which are high in level are generally better paid, less repetitive, provide more freedom and require less physical effort than other jobs lower in level. Besides this, opportunity for self expression, self actualization and salary are found to be the main aspect which raise the job satisfaction of employees at higher occupational levels. In a study Kline and Boyd ${ }^{11}$ (1991) also found that respondents at the highest management level reported highest job satisfaction. So it was expected that managers would show higher job satisfaction.

Table 1 (b)

Job satisfaction of employees: Difference between staff and managers in public and private sector banks

\begin{tabular}{|c|c|c|c|}
\hline Employee group & Employees below & $\begin{array}{l}\text { Employees above } \\
\text { median }\end{array}$ & Total \\
\hline Staff & $57(43 \%)$ & $75(57 \%)$ & 132 \\
\hline Manager & $37(44)$ & $47(56 \%)$ & 84 \\
\hline Total & 94 & 122 & 216 \\
\hline \multicolumn{4}{|c|}{ Chi square for public sector banks $=.0157$ Degree of freedom $=1$} \\
\hline Staff & $35(50 \%)$ & $37(50 \%)$ & 72 \\
\hline Manager & $25(44 \%)$ & $26(56 \%)$ & 51 \\
\hline Total & 60 & 63 & 123 \\
\hline \multicolumn{4}{|c|}{ Chi square for private sector banks $=.0020$ Degree of freedom $=1$} \\
\hline Staff & $66(50 \%)$ & $66(50 \%)$ & 132 \\
\hline Manager & $37(44 \%)$ & $47(56 \%)$ & 84 \\
\hline Total & 103 & 113 & 216 \\
\hline
\end{tabular}

However, no significant difference was found between job satisfaction of staff with that of managers in both public and private sector banks. Findings were further contrary to those of Porter \& Lawler ${ }^{35}$ (1968), Singh $\&$ Srivastava $^{36}$ and Morse $^{37}$ (1953) who evidenced that supervisors were more satisfied than non- supervisors.

\subsection{Relationship between job satisfaction and other organizational culture variables}

Age: A positive relationship was expected between job satisfaction and age of employees. A significant relationship between job satisfaction and age of employees was found in 'public' sector banks only. Benard and Gerhard $^{38}$ (1981) also found out that older workers were more satisfied with job than younger workers. So findings in public sector banks were in agreement with those of Bernard and Grehard.

Length of Service: A positive relationship was also expected between length of service and job satisfaction of employees. This relationship was also significant in 'public' sector banks only. In this context Sharma and Bhaskar $^{32}$ has stated that, "With the passage of time, employees with longer tenure develop greater ties with and stakes in their career and the organization. This is why we find a significant correlation between job satisfaction and both length of service as well as age"

Gender: Findings of Hulin and $\mathrm{Smith}^{40}$ failed to point out any consistent differences in job satisfaction between the sexes. So, it was expected that no significant relationship would exist between gender and job satisfaction of employees. Findings were supported by the absence of statistical significance in Chi square results in both public and private sector banks.

Organizational goal identity: A relationship was found between organizational goal identity and job satisfaction of staff in 'public' sector banks. Locke also found job satisfaction to be the function of the degree of congruence between individual's needs and the goal of the organization. Thus, findings in case of staff in public sector banks supported those of Locke. The relationship was not significant for staff in private sector banks and for managers in both types of banks.

Employee sociability: Employee sociability was found to have significant relationship with job satisfaction of only 'staff' in both public and private sector banks. Social interactions were probably more satisfying for staff in both public and private sector banks. The relationship was not significant for managers in these banks.

Team Orientation: A positive relationship was found between team orientation and job satisfaction in 'public' sector banks. The relationship was found to be significant in 'private' sector banks. Probably in private sector banks working in teams were more common which might not be the case in public sector banks. So, team orientation was more likely to lead a higher job satisfaction in public sector banks. 
Interpersonal trust, Cooperation among peers also related positively with job satisfaction of employees in public sector banks. Besides, interpersonal trust and cooperation among peers on one side also related significantly with the job satisfaction of managers in private sector banks. Interpersonal trust and cooperation among peers were not found to associate significantly with job satisfaction of staff in private sector banks.

Union management cooperation: In public sector banks, the Chi square values of 12.04 (4 d.f) in case of staff and that of 10.23 (4 d.f) in case of managers also revealed that cooperation between unions and management could also be very helpful in raising the job satisfaction level of employees.

Table 2 (a)

Relationship between job satisfaction of staff and other organizational culture variables in public and private sector banks

\begin{tabular}{|l|l|l|l|}
\hline & & \multicolumn{3}{|l|}{ Chi square value of "staf" } \\
\hline Sr. No. & Variable & Public sector Banks & Private sector Banks \\
\hline 1 & Communication efficacy & 0.458 & 2.959 \\
\hline 2 & Interpersonal trust & 10.559 & 11.998 \\
\hline 3 & Employee consultation in decisions & 8.167 & 8.931 \\
\hline 4 & Task orientation & 15.076 & 11.392 \\
\hline 5 & Employee initiatives & 22.81 & 5.433 \\
\hline 6 & Management's concern for employees & 32.85 & 10.52 \\
\hline 7. & Receptiveness to change & 18.153 & 6.919 \\
\hline 8. & Opportunities for advancement & 12.407 & 16.972 \\
\hline 9. & Cooperation among peers & 17.983 & 5.511 \\
\hline 10. & Employee sociability & 12.106 & 11.873 \\
\hline 11. & Team orientation & 17.934 & 5.531 \\
\hline 12. & Organizational goal identity & 16.712 & 11.873 \\
\hline 13. & Administrative efficacy & 16.411 & 5.531 \\
\hline 14. & Relationship orientation & 16.522 & 3.539 \\
\hline 15. & Union- management cooperation & 12.04 & - \\
\hline 16. & Age & 17.02 & 6.457 \\
\hline 17. & Length of service & 10.713 & 4.161 \\
\hline 18. & Gender & 0.786 & 0.376 \\
\hline
\end{tabular}

** Significant at $1 \%$ level $*$ Significant at $5 \%$ level

Degrees of freedom (in case of age) $=6$, (in case of Gender) $=2$

Degrees of freedom (in all other cases) $=4$

Friedlander and Margulies ${ }^{3}$ found that employee-centered climate is more related to job satisfaction than taskoriented climate. So it was expected that relationship orientation and management's concern for employees on one side would be positively related with job satisfaction on the other side. A negative relationship was further expected between task orientation and job satisfaction.

Table 2(b)

Relationship between job satisfaction of managers and other organizational culture variables in public and private sector banks

\begin{tabular}{|l|l|l|l|}
\hline & & \multicolumn{2}{|l|}{ Chi square value of "staff" } \\
\hline Sr. No. & Variable & Public sector Banks & Private sector Banks \\
\hline 1 & Communication efficacy & 1.279 & 8.504 \\
\hline 2 & Interpersonal trust & 3.222 & 11.998 \\
\hline 3 & Employee consultation in decisions & 8.79 & 3.869 \\
\hline 4 & Task orientation & 24.456 & 9.581 \\
\hline 5 & Employee initiatives & 10.618 & 5.508 \\
\hline 6 & Management's concern for employees & 1.16 & 10.28 \\
\hline 7. & Receptiveness to change & 24.943 & 7.076 \\
\hline 8. & Opportunities for advancement & 10.618 & 15.283 \\
\hline 9. & Cooperation among peers & 18.579 & 12.097 \\
\hline 10. & Employee sociability & 7.7126 & 7.580 \\
\hline 11. & Team orientation & 15.323 & 6.688 \\
\hline 12. & Organizational goal identity & 5.8217 & 4.559 \\
\hline
\end{tabular}




\begin{tabular}{|l|l|l|l|}
\hline 13. & Administrative efficacy & 15.180 & 8.09 \\
\hline 14. & Relationship orientation & 16.296 & 11.32 \\
\hline 15. & Union- management cooperation & 10.23 & - \\
\hline 16. & Age & 28.233 & 9.275 \\
\hline 17. & Length of service & 2.801 & 4.523 \\
\hline 18. & Gender & 1.4703 & 1.101 \\
\hline
\end{tabular}

** Significant at $1 \%$ level * Significant at $5 \%$ level

Degrees of freedom (in case of age) $=6$, (in case of Gender) $=2$

Degrees of freedom (in all other cases) $=4$

Relationship orientation: A positive relationship was found between relationship orientation and job satisfaction of employees in both public and private sector banks. Findings also supported those of Kazca and Kirk. ${ }^{5}$

Task orientation: Although a negative relationship was expected, task orientation was found to relate positively with the job satisfaction in both public and private sector banks.

Management's concern for employees: A positively relationship was found between management's concern for employees and job satisfaction of staff in both public and private sector banks. As far as managers were concerned those in private sector banks showed higher job satisfaction with higher concern for employees but the relationship was found to exist for managers in public sector banks.

Employee consultation in decisions: A positively relationship was expected between job satisfaction of employees and their consultation in decisions. However, no significant relationship was found regarding this in both public and private sector banks. Findings were contrary to those of Singh and Pestonjee ${ }^{22}$.

Receptiveness to change: It was found that in 'public' sector banks employees could also feel highly satisfied from job with higher receptiveness to change. The relationship between receptiveness to change and job satisfaction of employees was not to exist in 'private' sector banks.

Opportunities for advancement: Lambert $^{42}$ found that jobs that provided worker with the opportunity to do a variety of tasks and to do work that is personally meaningful promoted job satisfaction. Further Venkatachalam, Reddy and Samiullah ${ }^{43}$ stated that, 'each individual tries to better his job prospects. Since work is central to an individual's life, he tries to move upward in his job and this would lead to higher satisfaction in job. Thus its assumed a positive relationship between job satisfaction and opportunities for advancement. The findings were fully in agreement in the desired direction in both public and private sector banks.

Employee Initiatives: Employee initiatives related positively with job satisfaction of both staff and managers in 'public' sector banks only. The relationship was not significant in 'private' sector banks.

\subsection{Bank wise Comparsion}

\subsubsection{Bank wise comparison of job satisfaction of 'staff' in public and private sector banks.}

Staff of Punjab and HDFC bank evidenced significantly higher job satisfaction level as compared to all public sector banks. It was found earlier that these two private sector banks scored significantly higher in majority of the dimensions of organizational culture.

There was significant difference in the job satisfaction of staff in UTI bank and that in Punjab and Sind bank ( $\mathrm{T}$ Value $=2.36$ ). Staff of ICICI bank, showed significantly lesser satisfaction from their job as compared to staff of Bank of Punjab (T Value $=2.32$ ).

4.3.2 Bank wise comparison of job satisfaction of 'managers' in public and private sector banks.

There was a significant difference between the job satisfaction of managers in Bank of Punjab and managers of all public sector banks. Managers of ICICI bank reported significantly lesser satisfaction from their job as compared to that in Bank of Punjab (T value $=2.48$ )

\subsubsection{Bank wise comparison between job satisfaction of 'staff' and 'managers' in public and private sector} banks.

Although statistical analysis showed that staffs in both public and private sector banks were significantly less satisfied from their jobs than managers, bank wise comparison did not reveal any significant difference between the job satisfaction level of staff with that of managers in both public and private sector banks 
Table 3

Bank wise comparison: Job satisfaction of 'staff' and 'managers' in public and private sector banks

\begin{tabular}{|c|c|c|c|}
\hline Bank I & Bank II & $\begin{array}{l}\text { T- Values for } \\
\text { 'staff' }\end{array}$ & $\begin{array}{l}\text { T- Values for } \\
\text { 'managers' }\end{array}$ \\
\hline ICICI bank & State bank of India & .99 & .25 \\
\hline ICICI bank & Indian bank & .97 & .69 \\
\hline ICICI bank & Punjab and Sind bank & 1.74 & -.11 \\
\hline ICICI bank & Punjab and National bank & .61 & -.59 \\
\hline IndusInd bank & State bank of India & 1.41 & 1.01 \\
\hline IndusInd bank & Indian bank & 1.23 & 1.80 \\
\hline IndusInd bank & Punjab and Sind bank & 1.92 & .56 \\
\hline IndusInd bank & Punjab and National bank & 1.46 & .15 \\
\hline UTI bank & State bank of India & 1.59 & 1.03 \\
\hline UTI bank & Indian bank & 1.45 & 1.14 \\
\hline UTI bank & Punjab and Sind bank & 2.36 & .63 \\
\hline UTI bank & Punjab and National bank & 1.41 & .26 \\
\hline IDBI bank & State bank of India & 1.38 & 1.51 \\
\hline IDBI bank & Indian bank & 1.22 & 2.04 \\
\hline IDBI bank & Punjab and Sind bank & 1.95 & .95 \\
\hline IDBI bank & Punjab and National bank & 1.34 & .50 \\
\hline Bank of Punjab & State bank of India & 4.87 & 3.91 \\
\hline Bank of Punjab & Indian bank & 3.66 & 3.86 \\
\hline Bank of Punjab & Punjab and Sind bank & 5.86 & 2.87 \\
\hline Bank of Punjab & Punjab and National bank & 4.66 & 2.09 \\
\hline HDFC bank & State bank of India & 3.03 & 1.24 \\
\hline HDFC bank & Indian bank & 2.34 & .74 \\
\hline HDFC bank & Punjab and Sind bank & 3.69 & .31 \\
\hline HDFC bank & Punjab and National bank & 3.05 & .48 \\
\hline
\end{tabular}

Significant at $1 \%$ level significant at $5 \%$ level

Table 4

Bank wise comparison between the job satisfaction of staff and managers

\begin{tabular}{|l|l|}
\hline Bank & T values \\
\hline ICICI bank & .595 \\
\hline IndusInd bank & .757 \\
\hline UTI bank & .036 \\
\hline IDBI bank & .129 \\
\hline Bank of Punjab & .141 \\
\hline HDFC bank & 1.05 \\
\hline State bank of India & -.336 \\
\hline Indian bank & -.108 \\
\hline Punjab and Sind bank & -1.88 \\
\hline Punjab National bank & -.840 \\
\hline
\end{tabular}

\section{Conclusion}

- There was a significant and positive association between job satisfaction of employees and the organizational culture in both public and private sector banks. Age and length of service were found to have significant relationship with the job satisfaction of employees in 'public 'sector banks only. Relationship orientation, task orientation and interpersonal conflict emerged out to be significant determinants of job satisfaction of employees in public and private sector banks.

- In 'public' sector banks, employees also showed higher satisfaction from their job with higher receptiveness to change, cooperation among peers, team orientation, organizational goal identity and union management cooperation. In 'private' sector banks it was interpersonal trust that could probably raise the satisfaction from job of employees.

- It was found that staff of bank of Punjab showed higher job satisfaction than that of other banks. These two banks have scored higher on majority of the dimensions of organizational culture. Staff of bank of Punjab found significantly higher social interaction in their bank and found higher cooperation among peers. Bank of Punjab staff also perceive highly team oriented climate with higher receptiveness to change, 
administrative efficacy and opportunities for advancement. Staff of bank of Punjab further reported a high task-high relationship oriented style of management in their bank where managers showed higher interest for employee consultation and the personal problems of employees.

- So, probably due this highly adaptive and effective organizational culture staff of Bank of Punjab showed significantly higher job satisfaction than that of the public sector banks. ICICI bank staff evinced lower satisfaction from their job probably due to higher task orientation and lesser employee orientation.

\section{Books:}

\section{References}

[1] Locke, E.A. "The nature and cause of job satisfaction", in Dunnettee, M.D. Handbook of industrial and organizational psychology, Rand Mc Mally, Chicago, 1976.

[2] Benard, I and Gerhand, S. "Intrinsic work characteristics and work situation on the influence of age, education, gender as intervening variable," Psychology, 40(3), 1981, pp, 238-258.

[3] Sharma and Bhaskar op. cit.

[4] Kline and Boyd op. cit. pp. 305-316

[5] Porter, L.W. and Lawler, E.E. "Managerial Attitudes and Performance", Homewood Irwin, 1968.

\section{Journal Papers:}

[6] Singh, A.P. and Srivastava, A.K. “Occupational level and job involvement”, Journal of Psychology Researchers, 19(2) 1975, pp.5859

[7] Carrel, M.R. and Elbert N.F. "Some personal and organizational determinants of job satisfaction of postal clerks", Academy of Management Journal, June 1974, pp. 368-373

[8] Hulin, C.L. and Smith, P.C. “A linear model of job satisfaction”, Journal of Applied Psychology, 49, 1965, pp. 209-216.

[9] Jagdish. "Relationship between job satisfaction and self evaluation of supervisors", Indian Psychology Review, 29, 1985, pp. 6-8 